\title{
Explaining Recent Crime Trends: Introduction to the Special Issue
}

\author{
Richard Rosenfeld ${ }^{1} \cdot$ David Weisburd ${ }^{2,3}$
}

Published online: 11 August 2016

(C) Springer Science+Business Media New York 2016

Crime is a dynamic social phenomenon; it changes in quantity and quality over time. The study of crime trends is as old as criminology itself, yet it is fair to say criminologists know less about the factors affecting change over time in crime rates than about those related to individual differences in criminal behavior. This is an important knowledge gap for both criminological theory and criminal justice policy. Theory suffers when the social conditions and changes that influence crime rates are unknown or misread, or when the results of cross-sectional research are used to explain temporal changes in crime. Policy is misinformed as a result. The papers compiled in this special issue are intended to advance the study of crime trends as a significant topic in its own right, with data, methods, and theoretical approaches specifically devoted to explaining change in crime rates over time.

In 2012 the National Institute of Justice (NIJ) provided funding for the National Academies of Sciences, Engineering, and Medicine to establish a Roundtable on Crime Trends. A roundtable is a mechanism the National Academies use to address topics that have not received substantial research attention or for which existing research results are inconsistent or inconclusive. Change over time in crime rates qualifies on all counts. Research scholars and practitioners meet over one or more years to discuss what is known about the topic, areas of incomplete or inconclusive research, and future directions for scientific inquiry. Unlike consensus studies or workshops, roundtables do not make recommendations to the Academies and do not issue final reports.

The Roundtable on Crime Trends brought together criminologists, economists, sociologists, policy analysts, public health researchers, and criminal justice practitioners to

Richard Rosenfeld

richard_rosenfeld@umsl.edu

$\triangle$ David Weisburd

david.weisburd@mail.huji.ac.il

1 Department of Criminology and Criminal Justice, University of Missouri - St. Louis, One University Blvd., St. Louis, MO 63121, USA

2 George Mason University, Fairfax, VA, USA

3 Hebrew University of Jerusalem, Mount Scopus, Jerusalem, Israel 
assess research on crime trends and the adequacy of existing explanations, with a strong focus on the crime decline in the United States over the past several decades. The Roundtable met twice a year over 3 years and invited subject experts to discuss the state of existing research on a broad range of issues related to the change over time in crime rates. We began by considering crime trends in other nations and US trends over the past two centuries as pertinent background for our major focus on change in US crime rates in recent decades. The remaining meetings considered the relationship between crime trends during the past several decades and:

- individual differences in antisocial behavior, using the "lead-crime" hypothesis as a case study;

- the criminal justice system;

- demographic change; and

- social institutions, including gender and the family, the economy, schools, and changes in the physical environment. ${ }^{1}$

A key cross-cutting issue addressed in nearly every meeting was the difference in crime trends by age, race, ethnicity, and gender, and the implications of these differences for explaining overall changes in crime rates.

The list of topics the Roundtable discussed is not exhaustive. We did not consider trends in white-collar, corporate, or governmental crime, or the rise and extent of cybercrime, for which existing data and research are very limited. Nor did we attempt to "solve" the recent crime drop by disclosing a single factor or explanation that would order all of the relevant fact patterns. We concluded that the pursuit of single-factor or universal explanations was not a productive avenue for advancing scientific inquiry on crime trends. We did build on the work of a previous Academies workshop on crime trends also sponsored by NIJ (see Goldberger and Rosenfeld 2008), and we committed ourselves from the outset to produce research papers based on our deliberations intended to shed additional light on issues in the literature that remain under-explored or unresolved. The papers in this special issue represent the first outgrowth of this effort. ${ }^{2}$

\section{The Current Issue}

The special issue begins with an article by Lauritsen, Rezey, and Heimer that compares crime rate trends based on the two major sources of crime data for the United States: the FBI's Uniform Crime Reports (UCR) and the Bureau of Justice Statistics' National Crime Victimization Survey (NCVS). ${ }^{3}$ They examine several correlates of trends in homicide and two measures of serious nonlethal violence, one based on UCR data and the other on NCVS data, over the period 1973-2012. The authors conclude that the timing of the crime drop in serious nonlethal violence differed according to the data source used to document it. The NCVS rate of serious violence began to decline well before the early 1990s, the commonly accepted starting point of the US crime drop based on UCR data.

\footnotetext{
1 For a listing of Roundtable members and meeting agendas, see http://sites.nationalacademies.org/ DBASSE/CLAJ/CurrentProjects/DBASSE_081065.

2 Additional papers are underway, including a "wraparound" paper that draws from the entire range of issues the Roundtable addressed.

3 See The Nation's Two Crime Measures (https://www.fbi.gov/about-us/cjis/ucr/crime-in-the-u.s/2011/ crime-in-the-u.s.-2011/crime-measures).
} 
The authors also find that several of the correlates they examined (e.g., unemployment, consumer pessimism, and inflation) are related to the NCVS trend but not to the UCR trend in serious nonlethal violence in the hypothesized direction. A notable result of their study is that a measure of gasoline lead exposure is positively related to the UCR trend in nonlethal serious violence, but is unrelated to the comparable NCVS trend. This result calls into question prior research on the lead exposure hypothesis for the crime drop based on UCR data (e.g., Reyes 2007). The import of this article is that "choice of data matters" both for describing and explaining the crime drop in the United States.

The three following articles take up key analytical issues in the study of crime trends. Kim, Bushway, and Tsao investigate the relative contribution of period and cohort effects to the decline in age-specific felony arrest rates in New York State between 1990 and 2010. Period effects occur at about the same time as the crime rate changes to which they are linked. Cohort effects influence current crime rates by altering the criminal propensities of age cohorts born at different points in time. The existing research literature on US crime trends is dominated by "period effect" explanatory factors (e.g., policing, imprisonment, contemporaneous economic conditions). Kim et al. find, however, that cohort effects outweighed period effects in the decline in New York felony arrests: age cohorts born after 1970 largely accounted for the overall decrease in felony arrests. This important study should move the study of cohort effects closer to the top of the crime trends research agenda.

The following article by Berg, Baumer, and Rosenfeld also considers an under-studied issue in the crime trends literature, whether changes in crime over time are a function of the declining prevalence or incidence of criminal offending. Prevalence refers to the fraction of the population that commits crime. Incidence refers to the frequency of crimes committed by active offenders. One or both of these factors may have influenced the recent crime drop, but they are rarely distinguished in prior research. Based on their analysis of longitudinal data from the Pittsburgh Youth Study, the authors find that declining prevalence rates largely explain the drop in violent and drug crimes committed by 17-18 yearold males between the beginning and end of the 1990s. By contrast, the decrease in property offending was a function of both declining prevalence and incidence.

Berg et al. do not offer evidence regarding the specific factors responsible for the declines in offending and incidence they document. The authors suggest they are likely to include a combination of cohort and period influences and call for future research on the conditions associated with change over time in offending prevalence and incidence. That research will have to be based on individual-level longitudinal datasets similar to the Pittsburgh Youth Study, because the commonly used data sources in crime trends research, such as the Uniform Crime Reports, confound the separate influences of prevalence and incidence on aggregate crime rates. We join the authors in recommending further efforts to replicate and build on their study.

Crime rates are not the only major social indicator to exhibit a decline in recent decades - teen childbearing has decreased as well. Colen, Ramey, and Browning ask whether many of the same social conditions and policies associated with the crime drop may also be implicated in declining teen fertility. Their analysis of US states finds that women's increasing educational attainment, the increase in the Hispanic and foreign born population, the rise of the service sector of the labor market, and state family planning services together account for over a quarter of the joint variation in teen fertility and violent crime between 1990 and 2010. The authors conclude that both declining fertility and crime are the product of a "complicated nexus of social conditions" and recommend that social scientists stop characterizing crime as primarily a male problem and teen fertility primarily 
a female problem. We might add that the crime drop is not simply a "crime problem" but one that shares underlying sources with other indicators of social change.

Rosenfeld and Levin analyze the relationship between crimes committed for monetary gain and another social indicator that has not figured centrally in recent research on crime trends: inflation. Price increases push up rates of robbery and property crime, they argue, by fueling demand for cheap stolen goods. As price increases abate, acquisitive crime rates should as well. They hypothesize that changing inflation rates contributed to the major swings in acquisitive crime in the United States during the past half century, and that historically low inflation rates help to explain why rates of acquisitive crime did not rise during the Great Recession of 2008-2009. Their time-series analyses yield evidence in support of both hypotheses. The authors conclude that inflation belongs in the suite of indicators used to explain both short- and long-run changes in crime rates.

Steenbeek and Weisburd examine the concentration of crime at different levels of spatial aggregation. Building on a growing body of research on the importance of micro geographic units in understanding the crime problem, the authors examine the extent to which the variability in crime is accounted for by street segments, neighborhoods, and districts of Den Hague, the Netherlands. This is the first study to directly nest street segments in these larger units. The findings reinforce earlier studies pointing to the importance of street segments in understanding crime, showing that most of the variance in the hierarchical models estimated derives from variability across street segments. The district level accounts for most of the remaining variance, with neighborhoods as defined in Den Hague adding little new to the models estimated.

The major implication of Steenbeek's and Weisburd's study for crime trends research is the importance of the areal unit chosen for analysis. In short, space matters when examining change in levels of crime over time. Underscoring this point, Steenbeek and Weisburd find that street segments accounted for an increasing proportion of the variability in crime over time in Den Hague. This suggests that the importance of different spatial units will change over time, which opens up a new area for exploration in studying crime trends.

The final article by Martinez, Stowell, and Iwama addresses the role of immigration in neighborhood-level homicide trends between 1960 and 2010 in San Diego. They show, contrary to popular and politically charged views, that the increase in Latino immigration was associated with declining homicide rates. The study reveals the benefits of integrating neighborhood-level criminological research, typically conducted in cross-sectional designs, with research on crime trends that is generally carried out at the national or state level of analysis. As such, the study challenges researchers to consider whether crosssectional analysis misrepresents the dynamic nature of crime and whether large spatial aggregations mask social processes that are more appropriately studied at the neighborhood level. Indeed, following Steenbeek and Weisburd, for some problems even the neighborhood may be too coarse an aggregation.

In summary, the special issue offers several guidelines for future research on the change in crime over time. First, in the study of crime trends, the type of data matters. Researchers should decide whether police-based or survey-based victimization data is the better choice for studying a particular issue. When in doubt, and the data are available, use both.

Second, whenever possible, the components of changing crime rates should be distinguished and analyzed. Crime rate changes may result from cohort or period effects. They may reflect changing prevalence or incidence in offending and victimization. These components constitute the analytical "guts" of crime trends and have important consequences both for criminological theory and empirical research. 
Third, crime trends likely share common causes with other social phenomena, which should prompt researchers to situate changing crime rates in broader social changes. The relationship between crime trends and trends in other social indicators also serves as a reminder that the study of crime trends is an interdisciplinary enterprise.

Fifth, geography matters in the study of crime trends. The pronounced spatial concentration of crime should prompt researchers to ask whether significant empirical patterns are obscured and vital information is lost by the use of highly aggregated units of analysis.

Finally, the fundamental lesson of the articles in this special issue and of the National Academies Roundtable on Crime Trends is that time matters in the study of crime. Crime is not a static phenomenon. Research designs that freeze crime and its correlates at a single moment in time misrepresent the dynamic nature of crime and are bound to produce misleading results. At the very least, future cross-sectional research on crime should be accompanied by strong methodological and theoretical justification. For most studies, however, the better alternative will be to employ research designs that reflect the ever changing character of crime.

\section{Appendix: Roundtable Members}

Richard Rosenfeld (Chair), Thomas Jefferson Professor of Criminology and Criminal Justice, University of Missouri-St. Louis

Jim Bueermann, President, Police Foundation

Shawn Bushway, Professor of Criminal Justice/Professor of Public Administration and Policy, University at Albany (SUNY)

Manuel Eisner, Professor, Institute of Criminology, University of Cambridge

George Gascón, District Attorney, San Francisco District Attorney's Office

Maxine Hayes, State Health Officer, Washington State Department of Health

David Hemenway, Professor, Harvard School of Public Health

Dan Isom, Retired Chief of Police, City of St. Louis, and Des Lee Professor of Policing and the Community Department Criminology and Criminal Justice, University of Missouri-St. Louis

Janet Lauritsen, Professor of Criminology and Criminal Justice, University of MissouriSt. Louis

The Honorable Cindy S. Lederman, Circuit Court Judge, Eleventh Judicial Circuit of Florida, Miami

Randolph Roth, Professor of History, Ohio State University

José A. Scheinkman, Theodore A Wells '29 Professor of Economics, Princeton University

María B. Vélez, Assistant Professor, University of New Mexico

David Weisburd, Distinguished Professor, Department of Criminology, Law and Society, George Mason University, and Walter E. Meyer Professor of Law and Criminal Justice, Faculty of Law, The Hebrew University 
Ex-Officio:

Jon B. Gould, Program Director, Law and Social Sciences Program, National Science Foundation

Nancy Rodriguez, Director, National Institute of Justice

Thomas Simon, Deputy Associate Director for Science, Division of Violence Prevention, National Center for Injury Prevention and Control, Centers for Disease Control and Prevention

Project Staff:

Malay Majmundar, Study Director

\section{References}

Goldberger A, Rosenfeld R (eds) (2008) Understanding crime trends. National Academies Press, Washington, DC

Reyes, JW (2007) Environmental policy as social policy: the impact of childhood lead exposure on crime. Working paper 13097. National Bureau of Economic Research, Cambridge 